\title{
Dietary mannan oligosaccharide enhances growth and survival of juvenile tiger shrimp Penaeus monodon against experimental challenge with Vibrio harveyi and white spot syndrome virus
}

\author{
N. FELIX, P. KALAIMANI ARASI* AND K. MANIKANDAN \\ Directorate of Incubation and Vocational Training in Aquaculture, ECR-Muttukadu - 603 112, Tamil Nadu, India \\ ${ }^{*}$ Fisheries College and Research Institute, Thoothukudi - 628 008, Tamil Nadu, India \\ e-mail:n.felix@tnfu.ac.in
}

\begin{abstract}
A 45-days feeding trial was conducted on juvenile tiger shrimps Penaeus monodon of size $0.997 \pm 0.098 \mathrm{~g}$ with diets containing Mannan oligosaccharides (Mos) at three graded levels (0.1, 0.2 and $0.3 \%)$. Maximum weight gain (1.353 g) was achieved in shrimps fed with $0.3 \%$ Mos concentration, followed by $0.2 \%$ Mos $(1.224 \mathrm{~g})$. Best feed conversion ratio (FCR) of 2.406 was registered in $0.3 \%$ Mos groups. Results indicate that there was a significant difference $(\mathrm{p}<0.01)$ in weight gain and FCR among the treatments. However, no statistical differences were observed on the specific growth rate (SGR), mean feed intake and survival rate. Feeding trial was followed by a 10 days challenge study with Vibrio harveyi by intramuscular injection and white spot syndrome virus (WSSV) by feeding WSSV infected tissues. Significantly higher survival rate was observed in the shrimp groups fed with $0.3 \%$ Mos $(66.67 \%)$ than the other treatments when challenged with $V$. harveyi. Tiger shrimps fed with $0.3 \%$ Mos, challenged with WSSV showed a significantly higher survival rate (66.67\%), followed by $0.2 \%$ Mos (50\%), $0.1 \%$ Mos (25\%) and control (25\%), on day 5 post-challenge. However, on day 10 post-challenge with WSSV, except in the groups fed with $0.3 \%$ Mos ( $16.67 \%$ survival), $100 \%$ mortality was noticed in all other diet groups. Therefore, it is concluded that dietary administration of Mos at $0.3 \%$ would enhance the growth and survival of tiger shrimp against $V$. harveyi. With respect to WSSV challenge, it appears that, though Mos at $0.3 \%$ had a positive effect on the shrimp, higher survival was not observed. Whether additional increment in Mos supplementation in the diet would positively affect the survival of tiger shrimps post-WSSV challenge, needs to be investigated further.
\end{abstract}

Keywords: Mannan oligosaccharides, Penaeus monodon, Survival, Vibrio harveyi, White spot syndrome virus, WSSV

\section{Introduction}

World production of farmed shrimp has been increasing every year due to increase in farming areas and higher stocking densities. Among the most traded aquaculture products, farmed shrimps have been the second most preferred choice. However, with rapid expansion in shrimp farming, more disease problems occurred that led to decline in production in leading countries (FAO, 2016). These problems caused losses that exceed more than $40 \%$ of global capacity impacting socioeconomic status (Stentiford et al., 2017). Of the infectious diseases, viral and bacterial infections have been found to cause most of the production loss in different parts of the world (Walker and Mohan, 2009; Saejung et al., 2011; Chang et al., 2012; Zhang et al., 2012). During the past decades, various antibiotics and chemotherapeutants were used in shrimp culture to treat bacterial infections. But, the prolonged use of antibiotics created disease-resistant bacteria in the environment and residues in the flesh of cultured animals (Holmstrom et al., 2003; Su et al., 2011). On the other hand, viral infection in shrimp has no effective therapeutic counter measures (Itami et al., 1994).
Vibriosis caused by Vibrio spp. has been admitted to be the most significant bacterial infectious disease in farmed fish and shellfish (Egidius, 1987). In recent years, luminescent bacteria, Vibrio harveyi has been recognised as an opportunistic pathogen in juvenile and adult shrimp (Peeralil et al., 2020). Among pathogenic viruses, white spot syndrome virus (WSSV) is one of the most virulent one which leads to massive production losses in countries that grow shrimp. It is characterised by rapid disease outbreak and mortality. The problem may be accelerated when proper management practices are not followed like poor water quality, over-crowding of shrimps and elevated temperature (Andrino et al., 2014). One approach to avoid disease problems in shrimp culture is to enhance the health and immunity of shrimps through improved nutrition. This led to increased research on various health-promoting feed additives like prebiotics and immunostimulants, to avoid disease outbreaks and to improve the immune system of cultured animals.

Prebiotics are a non-digestible food ingredient that undoubtedly affects the host organisms by inciting the 
growth and activity of microflora present in the gastrointestinal tract. Many prebiotics have been commercially established like inulin, fructooligosaccharide, transgalactooligosaccharide and mannan oligosaccharide (Mos). Among these, Mos is the most commonly used prebiotics in aquaculture (Sang et al., 2014). It can act as growth and immune stimulants similar to the mode of action of the beta-glucans (Fegan, 2003). Mos has indicated guarantee in smothering enteric pathogens, tempering the immune response and enhancing the integrity of intestinal mucosa in studies with chickens and turkeys (Savage and Zakrzewska, 1997; Spring et al., 2000; Iji et al., 2001). Improved growth, survival and immunity on the addition of dietary Mos application have been reported in Penaeus semisulcatus (Genc et al., 2007a), Panulirus ornatus (Sang and Fotedar, 2011), Penaeus (=Litopenaeus) vannamei (Zhang et al., 2012) and Penaeus monodon (Sang et al., 2014). A challenge trial in P. monodon fed Mos supplemented diets against Vibrio, indicated that Mos can enhance the immune competence of $P$. monodon (SBBU, 2020). Improved growth and immunity on supplementation of Mos and better protection against WSV infection of shrimps have been reported (Genc et al., 2007a; Daniels et al., 2010; Apines-Amar et al., 2014).

As limited reports are available on the effects of Mos on P. monodon, the present study was designed to investigate the effects of dietary mannan oligosaccharides on the growth and survival of juvenile tiger shrimp P. monodon, followed by testing the disease resistance in the experimental groups when challenged with $V$. harveyi and WSSV.

\section{Materials and methods}

\section{Experimental animals}

Healthy post-larval tiger shrimp, P. monodon (PL 18) were procured from commercial shrimp hatchery. The seeds were confirmed PCR negative for WSSV and were reared for 2 months in rectangular cement tanks (5000 1) filled with saline water $(25 \pm 1 \%$ ) from a bore well. The shrimps were fed with commercial shrimp feed two times a day (CP Feeds Pvt. Ltd., Thailand). Faecal matter and uneaten feed were removed daily before each feeding. After 2 months, the juvenile shrimps were transferred and acclimatised in 451 experimental troughs for two weeks prior to start of the experiment.

\section{Bacterial strain and virus}

Luminous bacteria $V$. harveyi and WSSV infected tiger shrimps were used for the challenge trials. Both were obtained from the bacteriology and virology unit of Fisheries College and Research Institute, Thoothukudi,
Tamil Nadu, India. The identification of $V$. harveyi was carried out by the biochemical tests as described by West (1984) and confirmed by diagnostic methods described by Ransangan et al. (2012). The WSSV infected shrimps were confirmed by PCR analysis. Infected tissues were maintained at $-70^{\circ} \mathrm{C}$ in ultra-low temperature freezer (New Brunswick Scientific Pvt. Ltd., USA) until used.

\section{Preparation of test diets}

Commercial shrimp feed (CP Feeds Pvt. Ltd., Thailand) was used as a basal feed in the experiment. The basal feed contained 38\% protein, 5\% fat, $4 \%$ fibre and $12 \%$ moisture. Mannan oligosaccharides (Aqua-Mos) supplied by Alltech Biotechnology Pvt. Ltd., Bangalore, India was supplemented at three concentrations $(0.1,0.2$ and $0.3 \%$ ) to the basal diet as recommended by the manufacturer. The basal diet was coated with Mos using the binder 'Unigel' supplied by APC Nutrients Pvt. Ltd., Bangalore, India at a level of $80 \mathrm{ml} \mathrm{kg}^{-1}$ of feed. Test diets were air-dried at room temperature for 8-12 $\mathrm{h}$ and packed in airtight containers. Basal diet without Mos was used as control diet.

\section{Experimental set up}

Feeding trial was carried out for 45 days in the laboratory with shrimps of average initial weight $0.99 \mathrm{~g}$ in triplicates. The juvenile shrimps were weighed accurately in a digital electronic balance (Mettler Toledo, Switzerland) before the start of the experiment. Nursery reared and acclimatised juvenile shrimps of $P$. monodon were introduced into plastic troughs of 451 capacity filled with 401 of saline water $(25 \pm 1 \%$ ). In each plastic trough, 10 animals were stocked and continuous aeration was provided from a Hi-blow air pump (Takasuki, Japan) to maintain dissolved oxygen at $>5 \mathrm{ppm}$ in each trough. Water exchange (25\%) was carried out daily.

Shrimps of average initial weight $0.99 \mathrm{~g}$ were fed with test diets at $10 \%$ body weight daily, which was divided into two portions, one fed in the morning and the other in the evening. The feeds were given to the shrimps on a glass plate placed inside the troughs. The left-over feed was siphoned out after every feeding and oven-dried to assess the food conversion ratio (FCR). Faecal matter was removed in the morning, daily before feeding. Survival of the shrimps was observed throughout the experimental period and final body weight of the shrimps was recorded at the end of growth trial for calculation of growth related parameters.

\section{Evaluation of growth performances}

On termination of the experiment, growth performance of the shrimps were calculated using the following formulae (Kumar et al., 2015): 
Feed consumed $(\mathrm{g})=$ Total amount of feed given $(\mathrm{g})$ - Total amount of uneaten feed $(\mathrm{g})$

Mean feed intake $(\mathrm{g})=$ Total feed consumed $(\mathrm{g}) /[$ (Initial number of animals + Final number of animals) / 2]

Growth in terms of wet weight gain $=$ Final wet weight of shrimps (g) after 45 days of rearing - Initial wet weight of shrimps (g)

Food conversion ratio $(\mathrm{FCR})=$ Total feed consumed $(\mathrm{g}) /$ Wet weight gained $(\mathrm{g})$

Percentage survival $=[$ No. of shrimps survived at the end of the experiment / No. of shrimps stocked at the start of the experiment] $\mathrm{x} 100$

Specific growth rate $(\mathrm{SGR})=[(\ln$ of final mean wet weight - ln of initial mean wet weight) / Days of culture] x 100

Challenge trial

Shrimps from each treatment after the growth experiment were separated into two groups, one to challenge against $V$. harveyi and the other against WSSV, to assess the disease resistance of shrimps fed on Mos supplemented feeds.

\section{Median lethal dose (LD50) determination}

To determine the dose level of $V$. harveyi for challenging the shrimps fed on the feeds supplemented with Mos, LD50 value was estimated using juvenile shrimps with mean body weight of $2.5 \pm 0.13 \mathrm{~g}$. They were stocked at a rate of 6 nos. per trough in 451 capacity plastic troughs.

V. harveyi cultures were grown in trypticase soya broth supplemented with $2 \% \mathrm{NaCl}$ for 16-17 h (Jiravanichpaisal et al., 1994) and then inoculated into brain heart infusion agar in Roux bottles. The bacterial cultures were grown overnight and harvested in sterile saline. The cells were then washed in sterile saline and serially diluted to get cell concentrations of $10^{0}, 10^{-1}, 10^{-2}, 10^{-3}, 10^{-4}$ up to $10^{-8} \mathrm{cfu} \mathrm{ml}^{-1}$.

Shrimps were injected with $100 \mu$ of serially diluted stock $\left(10^{0}, 10^{-1}, 10^{-2}, 10^{-3}, 10^{-4}\right.$ and sterile saline) between the fifth and sixth abdominal segment after immobilisation using the anaesthetic and sixth abdominal segment after immobilisation using the anaesthetic MS-222 (Sigma-Aldrich Inc.) at a concentration of $100 \mathrm{mg} \mathrm{l}^{-1}$ (Gunkel and Lewbart, 2008). The $\mathrm{LD}_{50}$ value was calculated by observing the mortality of shrimps for 10 days. They were observed every $1 \mathrm{~h}$ for the first $6 \mathrm{~h}$ post-injection. Subsequent monitoring was done every $12 \mathrm{~h}$ until termination of the trial. The $\mathrm{LD}_{50}$ value was calculated following the method of Reed and Muench (1938):

Negative $\log$ of $\mathrm{LD}_{50}$ time $=$ Negative $\log$ of dilution above $50 \%$ mortality + Proportionate distance

Proportionate distance between

2 dilutions @where in the 50\% = Mortality above 50\%-50\%

end point lies $\quad$ Mortality above 50\% - Mortality

below $50 \%$

The $\mathrm{LD}_{50}$ value assessed was $1.86 \times 10^{4} \mathrm{cfu}$ per shrimp

\section{Challenge study with $V$. harveyi}

To study the disease resistance of shrimps fed on diets supplemented with Mos, the shrimps from respective treatments of the growth trial were restocked in 451 plastic troughs at a stocking density of 6 shrimps per trough on the $46^{\text {th }}$ day. The challenge trial was conducted in duplicate along with control. All the shrimps from each test diet were injected intramuscularly with the $\mathrm{LD}_{50}$ dose (1.86x $10^{4}$ cfu per shrimp) at $100 \mu l$ per animal between the $5^{\text {th }}$ and $6^{\text {th }}$ abdominal segment. Survival was monitored for 10 days (Apines-Amar et al., 2014).

\section{WSSV challenge}

The WSSV challenge test was conducted on the $46^{\text {th }}$ day after the completion of the growth trial. Shrimps were challenged with WSSV by oral infection. They were fed minced WSSV tissue following the methods of Wang et al. (1999) and Tang et al. (2003) at 10\% of their body weight twice daily. Shrimps fed with 2-step PCR negative shrimp tissues served as control group. Mortality was recorded for 10 days and dead shrimps were removed and frozen at $-70^{\circ} \mathrm{C}$ for PCR analysis.

\section{WSSV diagnostic PCR}

WSSV challenged shrimp samples from each treatment were randomly selected and screened for single-step PCR to detect WSSV (Takahashi et al., 1996). Positive and negative controls were also run along with the samples. DNA was extracted from shrimp tissues using a DNA extraction kit (Bangalore Genei Pvt. Ltd., Bangalore, India).

\section{Water quality analysis}

The water quality parameters such as salinity, $\mathrm{pH}$, temperature, dissolved oxygen, ammonia and nitrite were recorded once in a week for 45 days in growth trial and twice weekly during the 10 days challenge trials (APHA, 2005). The water quality parameters recorded are given in Table 1.

\section{Statistical analysis}

Data were analysed using one-way analysis of variance and significance of the difference between treatments were assessed by Duncan's multiple range tests (Hoshmand, 1994). Data were expressed as mean \pm standard error of the mean (SEM) of three replicates.

\section{Results}

Growth, survival and food conversion ratio

The results of growth-related performance of tiger shrimp P. monodon fed diets supplemented with Mos for 45 days are presented in Table 2. Shrimps fed Mos at $0.3 \%$ 
Table 1. Water quality parameters recorded during the experimental period

\begin{tabular}{llll}
\hline \multirow{2}{*}{ Parameters } & \multirow{2}{*}{ Growth trial } & \multicolumn{2}{c}{ Challenge trial } \\
\cline { 3 - 4 } & & V. harveyi challenge & WSSV challenge \\
\hline Salinity $(\%)$ & $25 \pm 1$ & $7.4 \pm 0.4$ & $26 \pm 1$ \\
$\mathrm{pH}$ & $7.6 \pm 0.4$ & $27.5 \pm 1$ & $7.4 \pm 0.4$ \\
Temperature $\left({ }^{\circ} \mathrm{C}\right)$ & $27 \pm 2$ & $6.2 \pm 0.5$ & $26.5 \pm 1$ \\
Dissolved oxygen $(\mathrm{ppm})$ & $6.1 \pm 0.6$ & $0.027 \pm 0.004$ & $5.4 \pm 0.4$ \\
$\mathrm{NH}_{3}-\mathrm{N}(\mathrm{ppm})$ & $0.024 \pm 0.004$ & $0.033 \pm 0.003$ & $0.025 \pm 0.007$ \\
$\mathrm{NO}_{2}-\mathrm{N}(\mathrm{ppm})$ & $0.031 \pm 0.003$ & & $0.041 \pm 0.008$ \\
\hline
\end{tabular}

Table 2. Growth related performance of P. monodon fed with mannan oligosaccharides (Mos) supplemented diets

\begin{tabular}{lllll}
\hline Diet & Control & $0.1 \%$ Mos & $0.2 \%$ Mos & $0.3 \%$ Mos \\
\hline Initial mean weight $(\mathrm{g})$ & $0.910 \pm 0.013$ & $0.933 \pm 0.016$ & $1.018 \pm 0.033$ & $1.127 \pm 0.041$ \\
Final mean weight $(\mathrm{g})$ & $1.904^{\mathrm{c}} \pm 0.060$ & $1.969^{\mathrm{bc}} \pm 0.047$ & $2.262^{\mathrm{ab}} \pm 0.049$ & $2.48^{\mathrm{a}} \pm 0.074$ \\
Mean weight gain $(\mathrm{g})$ & $0.994^{\mathrm{c}} \pm 0.073$ & $1.036^{\mathrm{bc}} \pm 0.060$ & $1.244^{\mathrm{ab}} \pm 0.080$ & $1.353^{\mathrm{a}} \pm 0.066$ \\
SGR & $1.639 \pm 0.103$ & $1.658 \pm 0.086$ & $1.774 \pm 0.118$ & $1.753 \pm 0.079$ \\
Mean feed intake (g) & $2.912 \pm 0.094$ & $3.028 \pm 0.048$ & $3.131 \pm 0.114$ & $3.056 \pm 0.099$ \\
FCR & $3.140^{\mathrm{a}} \pm 0.013$ & $3.132^{\mathrm{a}} \pm 0.038$ & $2.790^{\mathrm{b}} \pm 0.134$ & $2.406^{\mathrm{b}} \pm 0.068$ \\
Survival (\%) & $93.33 \pm 4.71$ & $93.33 \pm 4.714$ & $93.33 \pm 4.71$ & $93.33 \pm 4.71$
\end{tabular}

Values are expressed as mean $\pm \operatorname{SEM}(\mathrm{n}=3)$ and values with different superscripts indicate significant differences $(\mathrm{p}<0.01)$ as determined by Duncan's multiple range test

attained maximum weight gain of $1.353 \mathrm{~g}$ followed by Mos at $0.2 \%(1.244 \mathrm{~g})$. The minimum weight gain of $0.994 \mathrm{~g}$ was observed in shrimps fed the control diet. Significant difference $(p<0.01)$ in weight gain was observed between control and groups fed Mos supplemented diets.

Mos at $0.2 \%$ showed the highest specific growth rate (SGR) of 1.774 followed by Mos at $0.3 \%$ (1.753). The lowest SGR of 1.639 was observed in the control group. However, no significant difference in SGR was observed among the groups. The mean feed intake was maximum $(3.131 \mathrm{~g})$ in shrimps fed on diets containing $0.2 \%$ Mos followed by $0.1 \% \operatorname{Mos}(3.028 \mathrm{~g})$. The control group showed a minimum feed intake of $2.912 \mathrm{~g}$. Analysis of variance showed that there was no significant difference in mean feed intake between treatments. Mos at $0.3 \%$ showed an FCR of 2.406. The control group showed poor FCR of 3.140 and it was closely followed by $0.1 \%$ Mos (3.132). A significant difference $(p<0.01)$ among treatments in FCR was observed. Similar survival of shrimps (93.33\%) was observed in all groups.

\section{Median lethal dose $\left(L D_{50}\right)$}

Challenge with $V$. harveyi resulted in mortalities of shrimp depending on injected doses and time of exposure. Shrimps challenged with doses of $1.86 \times 10^{6} \mathrm{CFU}$ per shrimp showed $100 \%$ mortality within $12 \mathrm{~h}$ and $1.86 \mathrm{x}$ $10^{5} \mathrm{CFU}$ per shrimp showed $83 \%$ mortality within $24 \mathrm{~h}$. At a challenge dose of $1.86 \times 10^{4} \mathrm{CFU}$ per shrimp, $50 \%$ mortality was observed and this was considered as the LD50 value.
Survival rates of shrimps against $V$. harveyi challenge

P. monodon fed with Mos supplemented diets for 45 days were challenged with $V$. harveyi approximating to that of $\mathrm{LD}_{50}$ value. All the shrimp groups fed the control and mannan oligosaccharides supplemented diets showed survival from 33.33 to $66.67 \%$ after challenge with $V$. harveyi at the end of 10 days. The highest survival of $66.67 \%$ was recorded in $0.3 \%$ Mos supplemented feed while the lowest survival of $33.33 \%$ was recorded both in $0.1 \%$ Mos supplemented diet and control groups, at the end of 10 days. A significant difference $(p<0.01)$ in survival of shrimps was observed among treatments.

Fig. 1 shows the survival rates of $P$. monodon through the challenge period of 10 days. The mortality of shrimps began on day 1 itself in all the groups fed Mos supplemented diets and control. The highest survival of $83.33 \%$ was recorded in $0.3 \%$ Mos while the lowest survival of $58.34 \%$ was recorded in the control group on day 1 . The highest survival of $83.33 \%$ was stabilised in $0.3 \%$ Mos groups until day 4. Survival of shrimps fed on 0.1 and $0.2 \%$ Mos were less compared to $0.3 \%$ Mos throughout the period.

The clinical signs observed in challenged shrimps were erratic swimming, lethargy and shrimps swam near the water surface of the experimental containers. Besides these clinical signs, discolouration was also observed in challenged shrimps. 


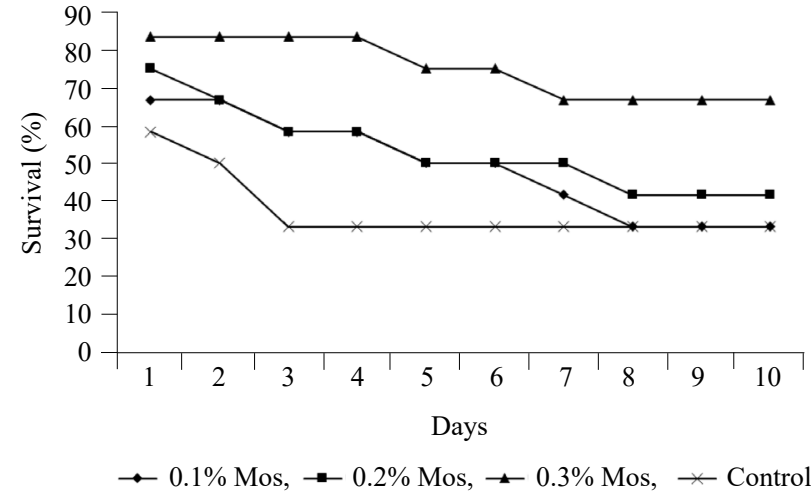

Fig. 1. Survival rates of $P$. monodon fed on diets supplemented with mannan oligosaccharides for 45 days and subsequently challenged with $V$. harveyi

\section{Survival rates of shrimps against WSSV}

The survival rates of $P$. monodon fed on diets supplemented with Mos after exposure to WSSV is presented in Fig. 2 and 3. Survival rates of the shrimps fed on feed supplemented with Mos at 0.2 and $0.3 \%$ were higher than that of the $0.1 \%$ Mos and control on day 5 after viral challenge. By day 5, 0.3\% Mos showed highest survival of $66.67 \%$ followed by $0.2 \% \operatorname{Mos}(50 \%)$. The lowest survival rate of $25 \%$ was registered both in $0.1 \%$ Mos and control diet. By day $6,100 \%$ mortality was observed in shrimps fed on diets supplemented with $0.1 \%$ Mos and control diet. Shrimps fed on diet supplemented with $0.2 \%$ Mos died by day 7 . At the end of 10 days experiment, survival of shrimps was observed only in $0.3 \%$ Mos fed shrimps and shrimps in none of the other treatments survived. The percentage of survival of shrimps fed $0.3 \%$ Mos was only $16.67 \%$. Though mortalities were observed in WSSV challenged groups, none in the control group (fed with 2-step PCR negative shrimp tissues) died until day 10. A significant difference in survival was observed among treatment groups exposed to WSSV for 5 days.

\section{Confirmation of WSSV infection}

Live shrimps from each treatment were randomly selected and tested for WSSV PCR diagnosis before the start of the challenge trial. It was found that shrimps in all the treatment groups were 2-step PCR negative for WSSV. Similarly, after WSSV challenge, the dead shrimps were tested for WSSV infection by PCR diagnosis and found that the shrimps in all the treatments were first step positive (Fig. 4). The clinical signs observed in challenged shrimps were lethargy, red discolouration and loss of appetite. Hoverer, they did not develop any white spots on their exoskeleton.

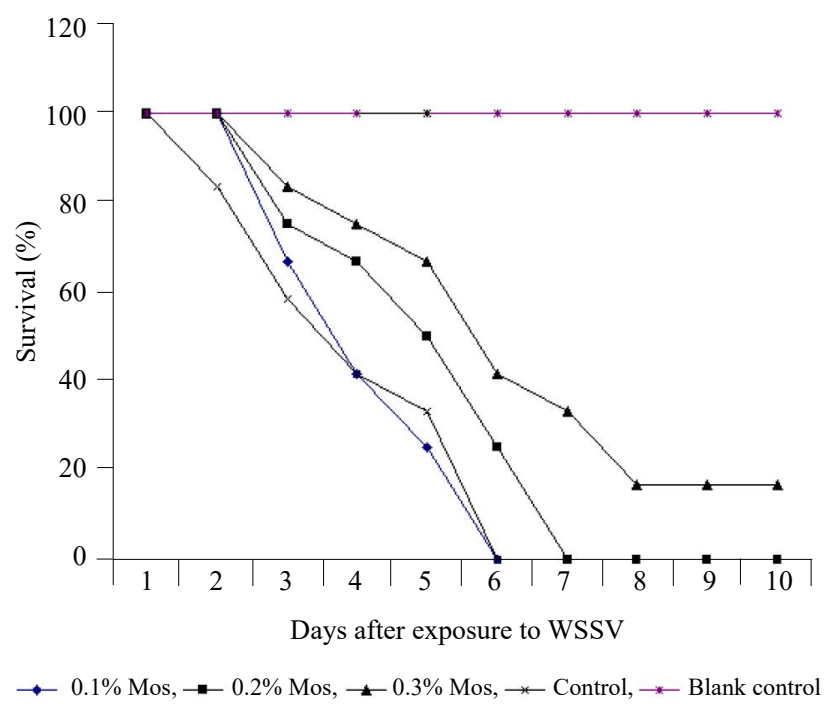

Fig. 2. Survival rates of $P$. monodon fed on diets supplemented with mannan oligosaccharides for 45 days and subsequently challenged with WSSV

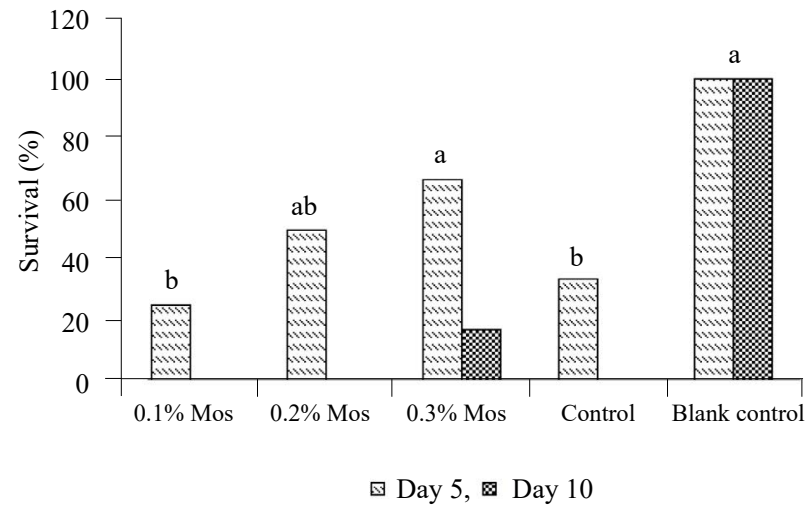

Fig. 3. Comparison of percentage survival of $P$. monodon challenged with WSSV on day 5 and 10 post-challenge. Different letters $(a, b)$ indicate significant $(p<0.01)$ difference in survival rates among the treatments

\section{Discussion}

Health-promoting additives in feeds help to enhance disease resistance. They can increase non-specific disease resistance and lead to a reduction in mortality (Chang et al., 2000). Our results showed that the dietary administration of Mos could enhance growth and disease resistance in P. monodon. In the growth trial, the mean weight gain, SGR and FCR were better in Mos treated shrimp groups at 0.2 and $0.3 \%$ levels as compared to control. Mos derived from the yeast cell wall are used as growth promoters (Fegan, 2003) and have been shown to improve feed conversion and reduce production costs in aquaculture systems (Spring, 2003). Similar results of improved weight gain, SGR 


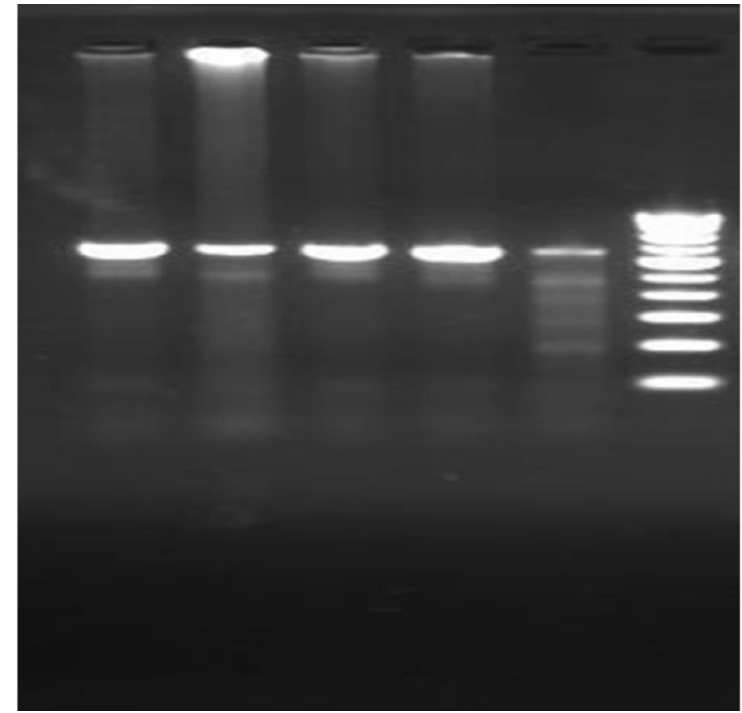

Fig. 4. DNA products amplified from shrimp samples using single-step standard diagnostic PCR protocol for WSSV in 1\% agarose gel. Lane 1: $0.1 \%$ Mos; Lane $2 ; 0.2 \%$ Mos, Lane 3: 0.3\% Mos; Lane 4: Control; Lane 5: Positive control; Lane 6: Molecular marker

and FCR were observed in P. semisulcatus (Genc et al., 2007a), P. ornatus (Sang and Fotedar, 2010), Homarus gammarus (Daniels et al., 2010), Astacus leptodactylus (Mazlum et al., 2011), Cherax destructor (Sang et al., 2011), P. vannamei (Zhang et al., 2012) and P. monodon (SBBU, 2002; Apines-Amar et al., 2014). Howes (1994) reported that Mos increased weight gain, survival and immune status of North American trout. Spring (2003) reported increased survival rates and FCR in red hybrid tilapia fed with Mos.

On the other hand, no significant difference in the growth performances was observed in Acipenser oxyrinchus desotoi (Pryor et al., 2003), hybrid tilapia (Genc et al., 2007b), Rachycentron canadum (Salze et al., 2008) and Sparus aurata (Dimitroglou et al., 2010). In the present study, shrimp groups fed $0.1 \%$ Mos showed no significant difference in weight gain compared to control. Contradictory to the results, Sang et al. (2014) observed that shrimp group fed Mos at $0.1 \%$ showed significant increase in weight gain than the control group. The above studies show that the effects vary with different aquatic animals and experimental conditions. Hence, the effects of dietary administration of Mos should be carefully verified before their use in the diets of different cultured animals. The values of ammonia and nitrite during the experimental period were within the tolerable limit of the animal studied (Sowers et al., 2004; Li et al., 2012).
Though there are studies in chickens and pigs with Mos, same related to fish and crustaceans are very limited. In the present study, during bacterial challenge test, shrimps fed Mos supplemented diets $(0.3 \%)$ showed enhanced disease resistance. It may be due to the prevention of attachment of Gram-negative cells of $V$. harveyi to the cells of the intestine of $P$. monodon and thereby it might have eliminated the colonisation of pathogenic bacteria as reported by Fegan (2003). Another possibility may be due to an increase in granular haemocytes in the haemolymph of the shrimps (SBBU, 2002). A similar result of higher haemocyte levels in the Mos fed shrimp groups were observed by Sang et al. (2014). The positive effect of Mos on the indigenous microbial population resulted in the stabilisation of the microbial community in the gastrointestinal (GI) tract, thereby suppressing the influx of new microbial communities from the rearing environment (Dimitroglou et al., 2009; Daniels et al., 2010). White et al. (2002) observed that Mos increased lactobacilli counts and higher serum IgG levels in weanling pigs. Rong et al. (2003) reported that Mos increased the number of $T$ lymphocytes and IgG content in weanling pigs. Roman (1999) observed that Mos reduced mortality of Atlantic salmon infected with salmonid rickettsia syndrome (SRS).

The results of the present study confirmed that Mos inclusion enhances immunity in P. monodon against WSSV. Only limited studies have been done on Mos inclusion to enhance resistance of fish and crustaceans against viral infection so far. However, there are works carried out with $\beta$-glucan, to enhance disease resistance against viral infection. Peptidoglycan administration in the diet extracted from Bifidobacterium thermophilum has been observed to improve the resistance of Penaeus japonicus against WSSV (Itami et al., 1998). Schizophyllan oral administration ( $\beta-1-3$ glucan) extracted from $S$. commune has shown to improve $P$. monodon resistance against WSSV infection (Chang et al., 1999; Chang et al., 2003). Apines-Amar et al. (2014) reported that the combined use of peptidoglycan and Mos has a significant effect when used in the diets of $P$. monodon at $0.2 \%$ supplementation. Similar results were obtained by Andrino et al. (2014), where the diets supplemented with $0.2 \%$ Mos and $\beta$-glucan enhanced the survival of juvenile $P$. monodon against WSSV. Chang et al. (2003) reported that all shrimps fed on diets containing beta-glucan at $0.1 \%$ level died by day 12 . In contrast, the day-12 survival rate of shrimp fed glucan at $1,0.2$ and $2 \%$ were $42.2,30$ and $24.4 \%$ respectively. Similarly, in the present experiment, shrimps fed on diets at lower concentrations of Mos ( 0.1 and $0.2 \%)$ died by day 10 , while the day-10 survival rate of shrimps fed Mos at $0.3 \%$ level was $16.67 \%$. 
The present study showed that Mos can be used as immunostimulants like $\beta$-glucan as it showed a better survival rate of $66.67 \%$ against $V$. harveyi and $16.67 \%$ against WSSV at the end of 10 days challenge experiments when fed at $0.3 \%$ concentration. Since higher survival rates were recorded at the highest concentration studied, further research is required to optimise the dose level of Mos. The present study did not address the mechanism by which Mos afforded protection against $V$. harveyi and WSSV. Hence, further studies are needed in this direction to elucidate the mechanism of action as well as to explore if additional increment in Mos supplementation in the diet would positively affect the survival of tiger shrimps post-WSSV challenge.

\section{Acknowledgements}

The authors wish to express gratitude to Dr. R. Santhanam, Dean, Fisheries College and Research Institute, Thoothukudi, Tamil Nadu, India for providing the facilities to carry out this research. The authors sincerely thank the authorities of Tamil Nadu Veterinary and Animal Sciences University, Chennai, India. This research was also supported by Fair and Lovely Foundation, Mumbai.

\section{References}

APHA 2005. Standard methods of the examination of water and waste water. $21^{\text {st }}$ edn. American Public Health Association, Washington, D. C., USA, 1220 pp.

Andrino, K. G. S., Apines-Amar, M. J. S., Janeo, R. L. and Corre Jr, V. L. 2014. Effects of dietary mannan oligosaccharide (MOS) and $\beta$-glucan on growth, immune response and survival against white spot syndrome virus (WSSV) infection of juvenile tiger shrimp Penaeus monodon. Aquaculture, Aquarium, Conservation and Legislation, 7(5): 321-332.

Apines-Amar, M. J. S., Andrino, K. G. S., Amar, E. C., Cadiz, R. E. and Corre Jr, V. L. 2014. Improved resistance against white spot virus (WSV) infection in tiger shrimp, Penaeus monodon by combined supplementation of peptidoglycan and mannan oligosaccharide (MOS). Extreme Life, Biospeology and Astrobiology, 6(1).

Chang, C. F., Chen, H. Y., Su, M. S. and Liao, I. C. 2000. Immunomodulation by dietary $\beta-1,3$-glucan in the brooders of the black tiger shrimp Penaeus monodon. Fish Shellfish Immunol., 10(6): 505-514. https://doi.org/10. 1006/fsim.2000.0266.

Chang, C. F., Su, M. S., Chen, H. Y. and Liao, I. C. 2003. Dietary $\beta$-1, 3-glucan effectively improves immunity and survival of Penaeus monodon challenged with white spot syndrome virus. Fish Shellfish Immunol., 15(4): 297-310. https://doi.org/10.1016/S1050-4648(02)00167-5.

Chang, C. F., Su, M. S., Chen, H. Y., Lo, C. F., Kou, G. H. and Liao, I. C. 1999. Effect of dietary $\beta$-1, 3-glucan on resistance to white spot syndrome virus (WSSV) in postlarval and juvenile Penaeus monodon. Dis. Aquat. Org., 36(3): 163-168. doi:10.3354/dao036163.

Chang, Y. P., Liu, C. H., Wu, C. C., Chiang, C. M., Lian, J. L. and Hsieh, S. L. 2012. Dietary administration of zingerone to enhance growth, non-specific immune response and resistance to Vibrio alginolyticus in Pacific white shrimp (Litopenaeus vannamei) juveniles. Fish Shellfish Immunol., 32(2): 284-290. https://doi.org/10.1016/j.fsi.2011.11.017.

Daniels, C. L., Merrifield, D. L., Boothroyd, D. P., Davies, S. J., Factor, J. R. and Arnold, K. E. 2010. Effect of dietary Bacillus spp. and mannan oligosaccharides (MOS) on European lobster (Homarus gammarus L.) larvae growth performance, gut morphology and gut microbiota. Aquaculture, 304(1-4): 49-57. https://doi.org/10.1016/j. aquaculture.2010.03.018.

Dimitroglou, A., Merrifield, D. L., Moate, R., Davies, S. J., Spring, P., Sweetman, J. and Bradley, G. 2009. Dietary mannan oligosaccharide supplementation modulates intestinal microbial ecology and improves gut morphology of rainbow trout, Oncorhynchus mykiss (Walbaum). J. Anim. Sci., 87(10): 3226-3234. https://doi.org/10.2527/ jas.2008-1428.

Dimitroglou, A., Merrifield, D. L., Spring, P., Sweetman, J., Moate, R. and Davies, S. J. 2010. Effects of mannan oligosaccharide (MOS) supplementation on growth performance, feed utilisation, intestinal histology and gut microbiota of gilthead sea bream (Sparus aurata). Aquaculture, 300(1-4): 182-188. https://doi.org/10.1016/j. aquaculture.2010.01.015.

Egidius, E. 1987. Vibriosis: pathogenicity and pathology A review. Aquaculture, 67(1-2): 15-28. https://doi.org/10. 1016/0044-8486(87)90004-4.

FAO 2016. The state of world fisheries and aquaculture 2016 Meeting the sustainable development goals. FAO Technical Publication, Food and Agriculture Organisation, Rome, Italy.

Fegan, D. 2003. Yeast more than just a raw material. Asian Aquac. Mag., September-October edn., p. 28-30.

Genc, M. A., Aktas, M., Genc, E. and Yilmaz, E. 2007a. Effects of dietary mannan oligosaccharide on growth, body composition and hepatopancreas histology of Penaeus semisulcatus (de Haan 1844). Aquac. Nutr., 13(2): 156-161. https://doi.org/10.1111/j.1365-2095.2007.00469.x.

Genc, M. A., Yilmaz, E., Genc, E. and Aktas, M. 2007b. Effects of dietary mannan oligosaccharides (MOS) on growth, body composition and intestine and liver histology of the hybrid Tilapia (Oreochromis niloticus $\times O$. aureus) Is. J. Aquac. Bamidgeh, 59: 10-16.

Gunkel, C. and Lewbart, G. A. 2008. Anesthesia and analgesia of invertebrates. In: Fish, R. E., Brown, M. J., Danneman, P. J. and Karas, A. Z. Anesthesia and analgesia in laboratory animals, $2^{\text {nd }}$ edn. Academic Press., Cambridge, Massachusetts, USA, p 535-542. 
Holmstrom, K., Graslund, S., Wahlstrom, A., Poungshompoo, S., Bengtsson, B. E. and Kautsky, N. 2003. Antibiotic use in shrimp farming and implications for environmental impacts and human health. Int. J. Food Sci. Technol., 38(3): 255-266. https://doi.org/10.1046/j.1365-2621.2003.00671.x.

Hoshmand, A. R. 1994. Experimental research design and analysis: A practical approach for agricultural and natural sciences. CRC Press, Boca Raton, Florida, USA.

Howes, D. 1994. Effect of Mannan oligosaccharide added to feed on growth performance and survival of North American trout. Lyons, T. P. and Jacques, K. A. (Eds.), Poster presented at $10^{\text {th }}$ Annual Symposium on Biotechnology in the Feed Industry. Nottingham University Press, Nottingham, UK.

Iji, P. A., Saki, A. A. and Tivey, D. R. 2001. Intestinal structure and function of broiler chickens on diets supplemented with a mannan oligosaccharide. J. Sci. Food Agric., 81(12): 1186-1192. https://doi.org/10.1002/jsfa.925.

Itami, T. 1994. Enhancement of disease resistance of kuruma prawn Penaeus japonicus-Increase in phagocytic activity of prawn haemocytes after oral administration of $\beta-1$, 3-glucan (Schizophyllan). Proceedings of the Third Asian Fisheries Forum. Asian Fisheries Society, Manila, Philippines.

Itami, T., Asano, M., Tokushige, K., Kubono, K., Nakagawa, A., Takeno, N., Nishimura, H., Maeda, M., Kondo, M. and Takahashi, Y. 1998. Enhancement of disease resistance of kuruma shrimp, Penaeus japonicus, after oral administration of peptidoglycan derived from Bifidobacterium thermophilum. Aquaculture, 164(1-4): 277-288. https://doi.org/10.1016/S0044-8486(98)00193-8.

Jiravanichpaisal, P., Miyazaki, T. and Limsuwan, C. 1994. Histopathology, biochemistry, and pathogenicity of Vibrio harveyi infecting black tiger prawn Penaeus monodon. J. Aquatic Anim. Health, 6(1): 27-35. https:// doi.org/10.1577/1548-8667(1994)006<0027:HBAPOV> 2.3.CO;2.

Kumar, S., Anand, P. S. S., De, D., Deo, A. D., Ghoshal, T. K., Sundaray, J. K., Ponniah, A. G., Jithendran, K. P., Raja, R. A., Biswas, G. and Lalitha, N. 2017. Effects of biofloc under different carbon sources and protein levels on water quality, growth performance and immune responses in black tiger shrimp Penaeus monodon (Fabricius, 1978). Aquac. Res., 48(3): 1168-1182. https://doi.org/10.1111/ are. 12958.

Li, Y., Yang, Q., Su, T., Zhou, F., Yang, L. and Huang, J. 2012. The toxicity of ammonia-N on Penaeus monodon and immune parameters. J. Shanghai Ocean Univ., 21(3): 358-362.

Mazlum, Y., Y1lmaz, E., Genç, M. A. and Guner, O. 2011. A preliminary study on the use of mannan oligosaccharides (MOS) in freshwater crayfish, Astacus leptodactylus Eschscholtz, 1823 juvenile diets. Aquac. Int., 19(1): 111-119. https://doi.org/10.1007/s10499-010-9345-4.
Peeralil, S., Joseph, T. C., Murugadas, V., Akhilnath, P. G., Sreejith, V. N. and Lalitha, K. V. 2020. Vibrio harveyi virulence gene expression in vitro and in vivo during infection in black tiger shrimp Penaeus monodon. Dis. Aquat. Org., 139: 153-160. https://doi.org/10.3354/dao03475.

Pryor, G. S., Royes, J. B., Chapman, F. A. and Miles, R. D. 2003. Mannanoligosaccharides in fish nutrition: Effects of dietary supplementation on growth and gastrointestinal villi structure in Gulf of Mexico sturgeon. North Am. J. Aquac., 65(2): 106-111. https://doi.org/10.1577/1548-8454 (2003)65<106:MIFNEO>2.0.CO;2.

Ransangan, J., Lal, T. M. and Al-Harbi, A. H. 2012. Characterisation and experimental infection of Vibrio harveyi isolated from diseased Asian seabass (Lates calcarifer). Malaysian J. Microbiol., 8(2): 104-115.

Reed, L. J. and Muench, H. 1938. A simple method of estimating fifty percent endpoints. Am. J. Epidemiol., 27: 493-497. https://doi.org/10.1093/oxfordjournals.aje.a118408.

Roman, M. 1999. Effect of different oligosaccharide supplements on mortality rate of salmon infected with Salmonide Rickettsia Syndrome. Poster presentation at Alltech's $15^{\text {th }}$ Annual Symposium on Biotechnology in the Feed Industry, Lexington, Kentucky, USA.

Rong, C. X., Bing, Z. J., Jun, L., Ping, W., Che, X. R., Yue, W. B., Zang J. J. and Lu, W. P. 2003. Effects of non-digestible oligosaccharide on diarrhoea control and performance of weanling pigs. Chin. J. Vet. Sci., 23(3): 92-294.

Saejung, C., Hatai, K., Wada, S., Kurata, O. and Sanoamuang, L. 2011. Clinical observations of black disease in fairy shrimps, Streptocephalus sirindhornae and Branchinella thailandensis, from Thailand and pathogen verification. J. Fish Dis., 34(12): 911-920. https://doi.org/10.1111/j. 1365-2761.2011.01314.x.

Salze, G., McLean, E., Schwarz, M. H. and Craig, S. R. 2008. Dietary mannan oligosaccharide enhances salinity tolerance and gut development of larval cobia. Aquaculture, 274(1): 148-152. https://doi.org/10.1016/j. aquaculture.2007.11.008.

Sang, H. M. and Fotedar, R. 2010. Effects of mannan oligosaccharide dietary supplementation on performances of the tropical spiny lobster juvenile (Panulirus ornatus, Fabricius 1798). Fish Shellfish Immunol., 28(3): 483-489. https://doi.org/10.1016/j.fsi.2009.12.011.

Sang, H. M., Kien, N. T. and Thanh Thuy, N. T. 2014. Effects of dietary mannan oligosaccharide on growth, survival, physiological, immunological and gut morphological conditions of black tiger prawn (Penaeus monodon Fabricius 1798). Aquac. Nutr., 20(3): 341-348. https://doi. org/10.1111/anu.12083.

Sang, H. M., Fotedar, R. and Filer, K. 2011. Effects of dietary mannan oligosaccharide on the survival, growth, immunity and digestive enzyme activity of freshwater crayfish, Cherax destructor Clark (1936). Aquac. Nutr., 17(2): e629-e635. https://doi.org/10.1111/j.1365-2095.2010.00812.x. 
Savage, T. F. and Zakrzewska, E. I. 1997. The performance of male turkeys fed a starter diet containing a mannan oligosaccharide. Zootecnica Int., 20: 30-33.

SBBU 2002. Report on the activity of Aqua Mos against Vibrios, Shrimp Biotechnology Business Unit, National Centre for Genetic Engineering and Biotechnolog, Bangkok, Thailand.

Sowers, A., Young, S. P., Isely, J. J., Browdy, C. L. and Tomasso Jr, J. R. 2004. Nitrite toxicity to Litopenaeus vannamei in water containing low concentrations of sea salt or mixed salts. J. World Aquac. Soc., 35(4): 445-451.

Spring, P. 2003. Using mannan oligosaccharide in modern nutrition. Asian Aquac. Mag., p. 30-31.

Spring, P., Wenk, C., Dawson, K. A. and Newman, K. E. 2000. The effects of dietary mannan oligosaccharides on cecal parameters and the concentrations of enteric bacteria in the ceca of salmonella-challenged broiler chicks. Poultry Sci., 79(2): 205-211. https://doi.org/10.1093/ps/79.2.205.

Stentiford, G. D., Sritunyalucksana, K., Flegel, T. W., Williams, B. A., Withyachumnarnkul, B., Itsathitphaisarn, O. and Bass, D. 2017. New paradigms to help solve the global aquaculture disease crisis. PLoS Pathogens, 13(2). DOI: 10.1371/journal.ppat.1006160.

Su, H. C., Ying, G. G., Tao, R., Zhang, R. Q., Fogarty, L. R. and Kolpin, D. W. 2011. Occurrence of antibiotic resistance and characterisation of resistance genes and integrons in Enterobacteriaceae isolated from integrated fish farms in South China. J. Env. Monit., 13(3): 229-236.

Takahashi, Y., Itami, T., Maeda, M., Suzuki, N., Kasornchandra, J., Supamattaya, K., Khongpradit, R., Boonyaratpalin, S., Kondo, M., Kawai, K. and Kusuda, R. 1996. Polymerase chain reaction (PCR) amplification of bacilliform virus (RV-PJ) DNA in Penaeus japonicus Bate and systemic ectodermal and mesodermal baculovirus (SEMBV) DNA in Penaeus monodon Fabricius. J. Fish Dis., 19(5): 399-403. https://doi.org/10.1111/j.1365-2761.1996.tb00379.x.

Tang, K. F., Durand, S. V., White, B. L., Redman, R. M., Mohney, L. L. and Lightner, D. V. 2003. Induced resistance to white spot syndrome virus infection in Penaeus stylirostris through pre-infection with infectious hypodermal and hematopoietic necrosis virus-A preliminary study. Aquaculture, 216(1-4): 19-29. https:// doi.org/10.1016/S0044-8486(02)00498-2.

Walker, P. J. and Mohan, C. V. 2009. Viral disease emergence in shrimp aquaculture: Origins, impact and the effectiveness of health management strategies. Rev. Aquac., 1(2): 125-154. https://doi.org/10.1111/j.1753-5131.2009.01007.x

Wang, Q., White, B. L., Redman, R. M. and Lightner, D. V. 1999. Per os challenge of Litopenaeus vannamei postlarvae and Farfantepenaeus duorarum juveniles with six geographic isolates of white spot syndrome virus. Aquaculture, 170(3-4): 179-194. https://doi.org/10.1016/ S0044-8486(98)00425-6.

West, P. A. 1984. Identification and classification of Vibrionaceae-An overview. Vibrios in the environment, John Wiley, New York, USA, p. 285-363.

White, L. A., Newman, M. C., Cromwell, G. L. and Lindemann, M. D. 2002. Brewers dried yeast as a source of mannan oligosaccharides for weanling pigs. J. Anim. Sci., 80(10): 2619-2628. https://doi.org/10.1093/ansci/80.10.2619.

Zhang, J., Liu, Y., Tian, L., Yang, H., Liang, G. and Xu, D. 2012. Effects of dietary mannan oligosaccharide on growth performance, gut morphology and stress tolerance of juvenile Pacific white shrimp, Litopenaeus vannamei. Fish Shellfish Immunol., 33(4): 1027-1032. https://doi. org/10.1016/j.fsi.2012.05.001. 